3

4

5

6

\title{
Zinc Solubilizing Plant Growth Promoting Microbes Produce Zinc Nanoparticles
}

\author{
Uzma Sultana $^{1}$, Suseelendra Desai ${ }^{1 *}$, Gopal Reddy ${ }^{2}$, TNVKV Prasad ${ }^{3}$ \\ ${ }^{1}$ Research scholar and Principal Scientist, respectively, Plant Pathology Laboratory, Division of \\ Crop Sciences, Central Research Institute for Dryland Agriculture, Santoshnagar, Saidabad, \\ Hyderabad - 500059, India \\ ${ }^{2}$ Emeritus Professor, Department of Microbiology, Osmania University, Hyderabad - 500007, \\ India \\ ${ }^{3}$ Principal Scientist, Institute of Frontier Technology, RARS, Acharya NG Ranga Agricultural \\ University, Tirupati - 517502, India \\ *Corresponding Author
}

\section{Abstract}

Strains of Pseudomonas, Bacillus and Azospirillum with plant growth promoting ability were checked for their zinc solubilizing ability. Efficient zinc solubilizers were checked for their ability to produce nano-scale zinc particles. The nanoparticles from the cell-free culture filtrates obtained from these strains were characterized for particle size, Zeta potential and functional groups. Presence of $\mathrm{Zn}$ nanoparticles in the bacterial culture filtrate was confirmed by particle distribution and Scanning electron microscope (SEM) analysis. Most properties of nanoparticles are size dependent. Zinc nanoparticles were observed to be spherical in shape and size ranged from 52.0 to $106.0 \mathrm{~nm}$. Zeta potential of the $\mathrm{Zn}$ nanoparticles was estimated to understand the stability of the particles. The measured zeta potentials varied from $-14.5 \mathrm{mV}$ to $+179.10 \mathrm{mV}$ indicating high stability and dispersion of the zinc nanoparticles. FTIR peaks at different wave numbers depicted the role of functional groups of proteins in the biosynthesis of $\mathrm{Zn}$ nanoparticles. This finding opens a new area of research focusing on microbe-microbe interactions in rhizosphere and plantmicrobe interactions at rhizosphere apart from biosynthesis of nanoparticles, which has major 
applications. To our knowledge, this is the first report of production of nanoparticles as part of nutrient mobilization by plant growth promoting rhizobacteria.

31 Keywords: Zinc Nano Particles, Pseudomonas, Bacillus, Azospirellum, FTIR, Zeta Potential

32 Corresponding author: desai1959@yahoo.com

Acknowledgements

34 The authors sincerely thank Director, ICAR-CRIDA for his constant support and encouragement to conduct this research at CRIDA. Senior author also acknowledges the fellowship from University Grants Commission (MANF scheme) and Dr. B. Suresh ARCI Hyderabad for

37 providing research facilities.

\section{Introduction}

Food- and nutritional-security are major concerns of most of the developing nations. Production of sufficient and nutritious food is a major challenge in front of many countries including India. Zinc $(\mathrm{Zn})$ is one of the vital minerals required for optimum plant growth as well as animals, including human beings such as mental retardations, impairments of the immune system and overall poor health. In recent years, the $\mathrm{Zn}$ deficiency problem has received increasing attention and appears to be the most serious micronutrient deficiency together with vitamin A deficiency. Zinc deficiency is particularly widespread among children and represents a major cause of child death world over. It plays a vital role in biochemical reactions in plants and its deficiency is displayed as a remarkable reduction in plant height and develops whitish-brown patches that turn necrotic subsequently (Hughes and Poole;1989). Zn occurs in soil as sphalerite, olivine, hornblende, augite and biotite and availability of $\mathrm{Zn}$ from these sources is guided by many factors among which bio-chemical actions of rhizo microorganisms play an important role (Bhupinder Singh 2005). The solubility of zinc is highly dependent upon soil $\mathrm{pH}$ and moisture and this is the reason why arid and semi-arid areas are zinc deficient. Most of the $\mathrm{Zn}$ in soil is in unavailable form and thus unable to meet nutritional requirements of plants. In India, $>50 \%$ of agroecosystems are $\mathrm{Zn}$ deficient, especially the Indo-Gangetic plains spanning across the States of Punjab and Uttar Pradesh. Overall, zinc deficiency in the country has increased from $42 \%$ to $49 \%$ in the past four decades and it is expected to increase up to 63\% by 2025 (Singh 2009). Plant response to $\mathrm{Zn}$ deficiency occurs in terms of membrane integrity loss, reduced synthesis of 
exogenously to plants in the form of chemical fertilizers like zinc sulphate that subsequently transforms (96-99\%) into different insoluble forms depending upon the soil types, physicochemical reactions and thus becomes totally unavailable in the environment within seven days of application (Rattan and Shukla 1991; Venkatakrishnan 2003). External supplementation of micronutrients is not only expensive, but also leads to unwanted accumulation of them in the soil in fixed forms. Accumulation of excess $\mathrm{Zn}$ complex leads to deterioration of soil-health, integrity and microbial diversity. Further, at a given point of time, plants need only small quantities of micronutrients. Efforts to supplement nutrients in the form of biofertilizers helped the rainfed farmers significantly (Venkateswarlu and Wani 1999). Strains of species of Pseudomonas, Bacillus, Azotobacter, Azospirillum and Acetobacter etc. are known to promote plant growth, (Kloepper 1991 and Orhan 2006). Solubilization of mineral nutrients; stimulation of root growth; and suppression of root diseases are some of the modes of actions of plant growth promoting rhizobacteria in influencing plant health and productivity (MartinezViveros 2010). Bacteria-mediated solubilization of phosphorus (P) to supplement $\mathrm{P}$ requirement of the plants is a popular technology among farmers in many countries (Cattelan 1999; Gull et al., 2004; Richardson et al 2009; Leo Daniel Amalraj et al., 2014). Similarly, Zn solubilization by microorganisms has been widely studied in fungi and bacteria (White et al., 1997; Di Simine et al., 1998; Fasim et al., 2002; Suseelendra Desai et al., 2012). Nanoparticles with small size and (Prasad 2012). Particle size may affect the agronomic effectiveness of $\mathrm{Zn}$ fertilizers. Decreased particle size results in increased number of particles per unit weight of applied $\mathrm{Zn}$. Decreased particle size also increases the specific surface area of a fertilizer, which should increase the dissolution rate of fertilizers with low solubility in water, such as zinc oxide ( $\mathrm{ZnO})$ (Mortvedt, 1992). Nanoparticles of $\mathrm{Mg}, \mathrm{Zn}, \mathrm{Fe}$ and $\mathrm{P}$ are the structural component of enzymes (phosphatases and phytase), polysaccharides and chlorophyll. In plants, nanoparticles can be applied for a broad range of uses, particularly to tackle Phytopathological infections, nutrition supplement and as growth adjuvant. These nanoparticles can be tagged to agrochemicals or other substances as delivery agent to plant system and tissues for controlled release of chemicals. They are known to stabilize the enzyme complexes in plants. First evidence of biosynthesis of nanoparticles was reported using Pseudomonas stulzeri where the nanoparticles were deposited on the cell membrane (Klaus 1999). Subsequently, Bacillus licheniformis (Kalimuthu 2008); Lactobacillus 
strains (Nair 2002); Bacillus subtilis (Saifuddin 2009); Cornybacterium sp. (Zhang 2005); and E.coli (Gurunathan 2009a; Gurunathan 2009b) were shown to be involved in extra and intracellular synthesis of nanoparticles. (Minaeian 2008) reported synthesis of silver 50-100 nm particles by Klebsiella pneumoniae, and Escherichia coli. While a number of reports are available on the biological synthesis of silver nanoparticles by potential endophytic microorganisms, scanty information is reported on the synthesis of $\mathrm{Zn}$ nanoparticles using plant growth promoting bacteria. In the present study, we report the ability of $\mathrm{Zn}$ solubilising rhizobacteria isolated from various crop production systems of different agro-ecological sub regions of India to produce $\mathrm{Zn}$ nanoparticles.

\section{Materials and methods}

Bacterial strains used in this study were obtained from the culture bank of ICAR-Central Research Institute for Dryland Agriculture, Hyderabad. Based on previous qualitative and quantitative screening, five efficient zinc solubilising strains viz. Bacillus B116, Pseudomonas P29, Pseudomonas P33, and Azospirillum 20 were selected for nanoparticle analysis (Praveen Kumar 2012).

All the isolates were grown in Minimal salt medium amended with $0.1 \% \mathrm{ZnO}$ with an initial population containing $2 \times 10^{8} \mathrm{CFU} / \mathrm{ml}$ and incubated at room temperature in an orbital shaking incubator with $180 \mathrm{rpm}$ speed. The culture medium was centrifuged after $72 \mathrm{~h}$ of inoculation and the supernatant was collected. Supernatant was analysed for the presence of nanoparticles in nanoparticle analyzer.

\subsection{Characterization of $\mathrm{Zn}$ nanoparticles}

Ten $\mathrm{mL}$ of the supernatant was transferred to a cuvette and placed into the nanoparticle analyzer (Horiba Nanoparticula 100). Three replicas for each sample were maintained respectively. Each sample was read three times and the mean was considered as particle size. The zeta potentials were recorded using Particle size analyzer (Horiba Nanoparticula 100, Japan). This apparatus uses Dynamic Light scattering (DLS) phenomenon. The sample holder temperature was maintained at $25^{0} \mathrm{C}$, a technique used to determine the stability profile of small particles in solution. Nano scale Zinc particles were observed under SEM. To observe nanoparticles of Zinc, $10 \mu 1$ of the suspension was spotted on to the metal slide. Metal slide was placed inside a desiccator over night 
119

120

121

122

123

124

125

126

127

128

129

130

131

\section{0}

141

142

143

144

145

146

to remove moisture completely. After removing the slide from the desiccator, a gold sputtering of approximately $1 \mathrm{~nm}$ was done over the suspension.

For Fourier Transform Infra Red (FTIR) spectroscopy measurement, the bio-transformed product present in cell-free filtrate was analyzed. FTIR spectrum (Bruker Tensor 27, USA) was recorded in mid IR region in the range of 400-4000 wavenumber $\mathrm{cm}^{-1}$. A drop of the sample solution was carefully added to the potassium bromide crystals using a micropipette and the spectrum was recorded in transmittance $(\%)$ mode.

\section{Results}

The results of the particle size distribution (PSD) dynamic light scattering method conforms the presence of Zinc nanoparticles. Particle Z-Average size and Poly dispersity index are presented in table 1.

Table1. Particle Z-Average size and Poly dispersity index of Zn nanoparticles produced by different bacterial strains in $\mathrm{ZnO}$ incorporated broth

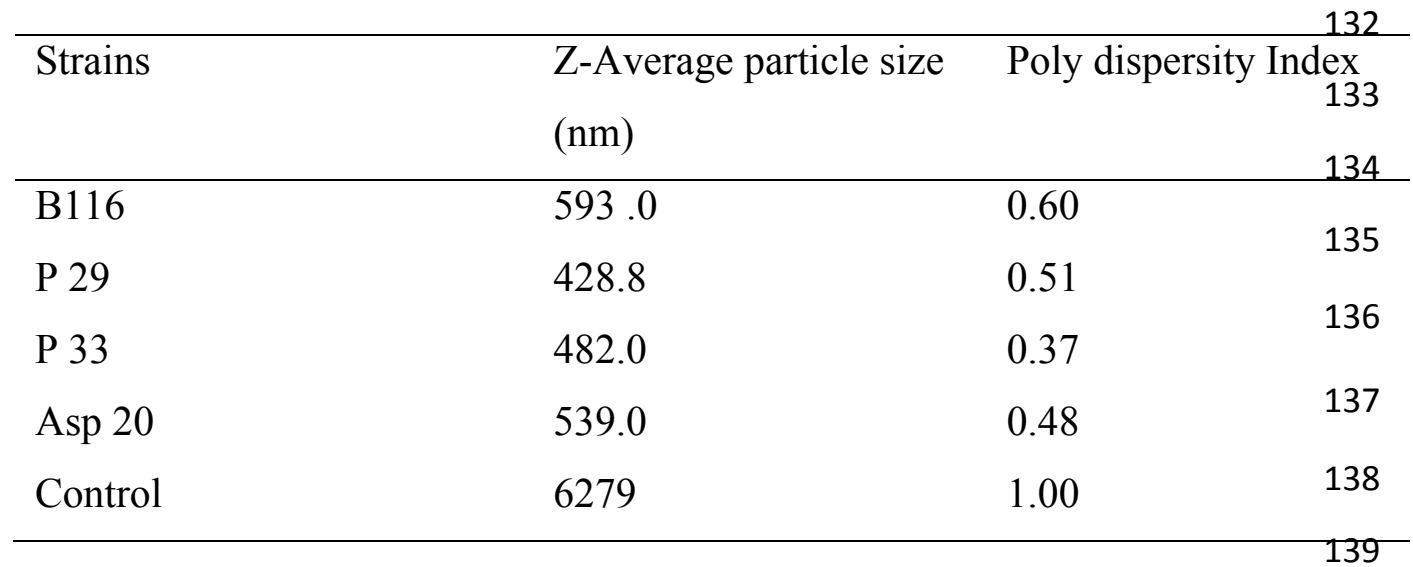

Electron Microscopy (SEM) analysis image provided further insight into the shape size, morphology and distribution of nanoparticles. The SEM micrographs recorded, showed spherical or roughly spherical nanoparticles, which were observed to be uniformly distributed. The drop coated film of the $\mathrm{Zn}$ nanoparticles were distributed on the surface and were uniformly dispersed with some aggregation. The size of the Zn nanoparticles ranged from 106 to $52 \mathrm{~nm}$. In control the size was 5200nm (Table 2 and Fig 1).

Table 2. Size of available $\mathrm{Zn}(\mathrm{nm})$ in MS medium amended with $\mathrm{ZnO}$

\begin{tabular}{|l|l|}
\hline Minimal salt media & Size (nm) \\
\hline
\end{tabular}




\begin{tabular}{|l|l|}
\hline amended with $\mathrm{ZnO}$ & \\
\hline Control & 5200 \\
B 116 & 106 \\
\hline P 29 & 52 \\
\hline P 33 & 74 \\
\hline Asp 20 & 53.4 \\
\hline
\end{tabular}
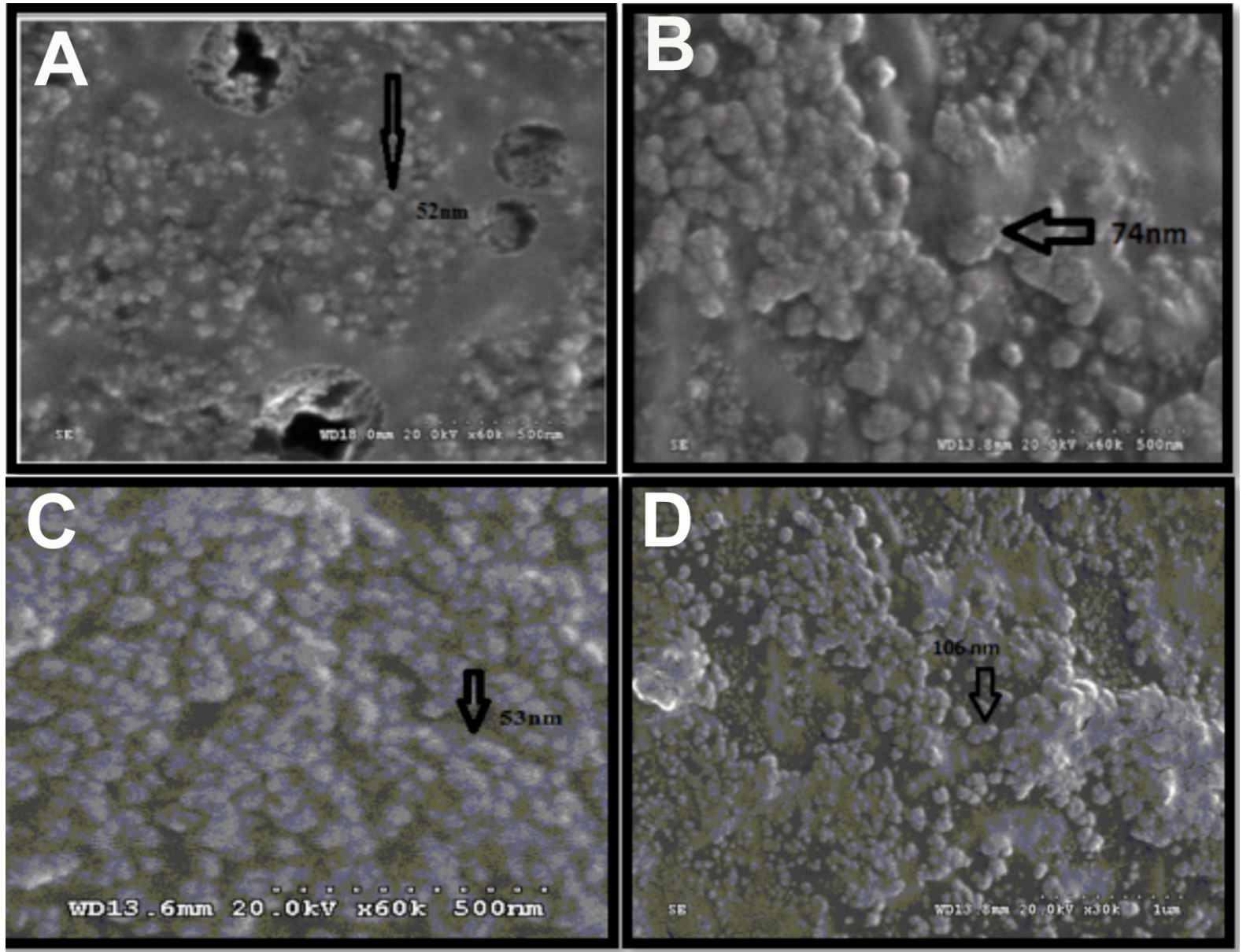

Fig1. SEM image of Nanoparticles of zn produced by a) P 29 (52nm) b) P 33 (74nm) c) Asp 


\subsection{Zeta Potential}

Using the nano particle analyzer, the Zeta potential was measured as the magnitude of ZetaPotential $(-200 \mathrm{mV}$ to $+200 \mathrm{mV})$ gives an indication of the potential stability of the colloidal system. The Zeta potentials of Zn nanoparticles produced by B116, P33, P29 and Asp20 were $+179.1 \mathrm{mV},-14.5 \mathrm{mV},+0.5 \mathrm{mV}$ and $0.5 \mathrm{mV}$ respectively, clearly indicating the stability of the nanoparticles (Fig 2).
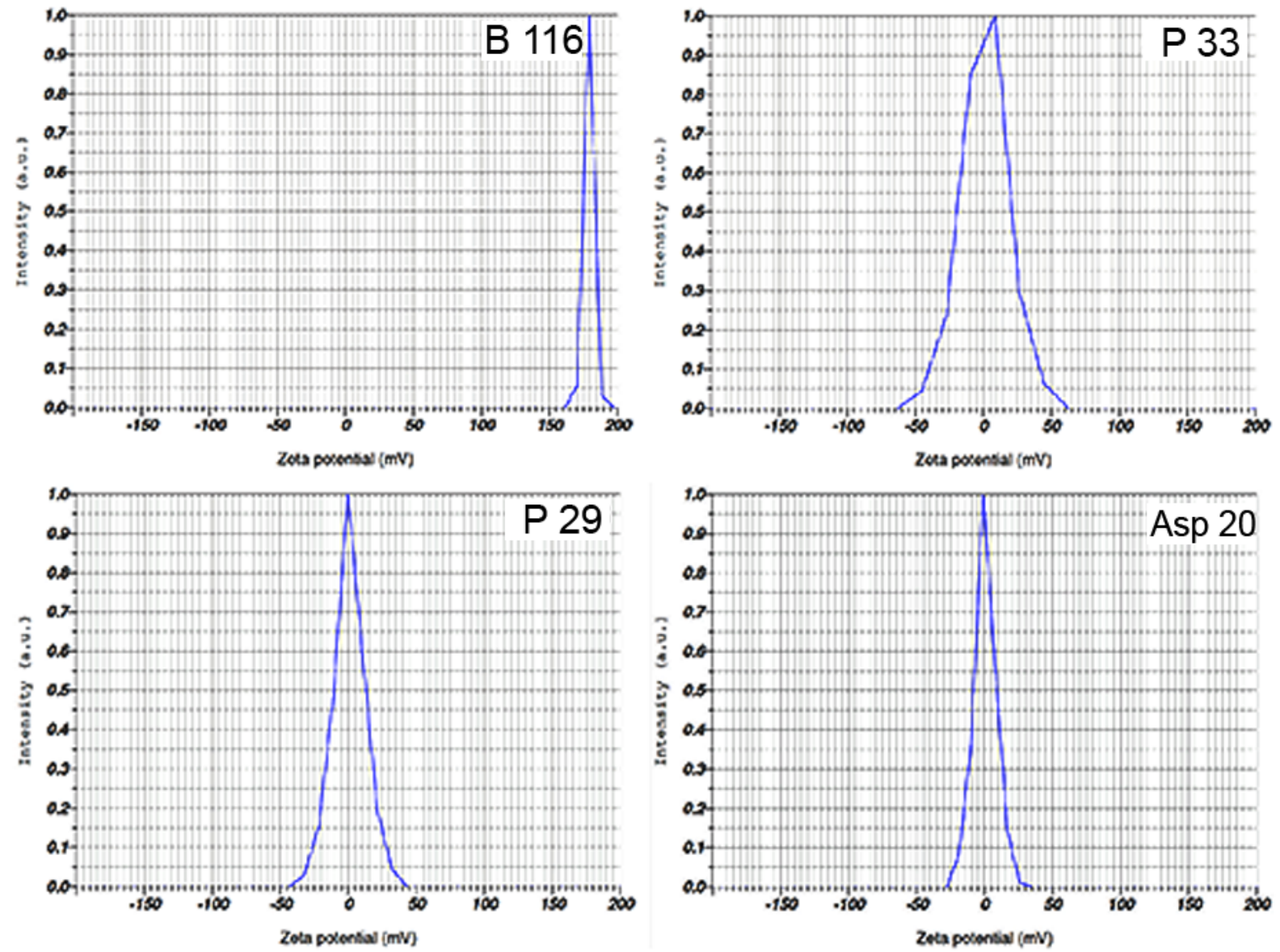

159

160

161

162

163

164

165

Fig2. Zeta potential of Zn nanoparticles produced by B116 (+179.1 mV), P33 (-14.5 mV), P29 (+0.5 mV), Asp 20 (+0.8 mV), and in ZnO amended MS medium

\subsection{FTIR Analysis}

FTIR analysis of the cell-free culture filtrates of $\mathrm{ZnO}$ amended MS medium was done to identify the interactions between $\mathrm{Zn}$ and bioactive molecules enabling synthesis and stabilization of $\mathrm{Zn}$ 
172 vibrations of $\mathrm{Zn}$ nanoparticles.

nanoparticles (Fig 3). The FTIR spectra of cell-free extracts of $\mathrm{ZnO}$ amended MS medium showed prominent peaks at 3346, 2923,1636, 1459 and 538 wave numbers $\mathrm{cm}^{-1}$. The strong broad wave at $3346 \mathrm{~cm}^{-1}$ is attributed to NH stretch of amides. The wave observed at $2923 \mathrm{~cm}^{-1}$ is stretch vibration of primary and secondary amides of protein. The band observed at $1636 \mathrm{~cm}^{-1}$ is assigned to the bending vibrational mode of amides. The peaks at 1459 refer to amino and aminomethyl stretching groups of protein. Peak observed at $529 \mathrm{~cm}^{-1}$ corresponds to the stretching
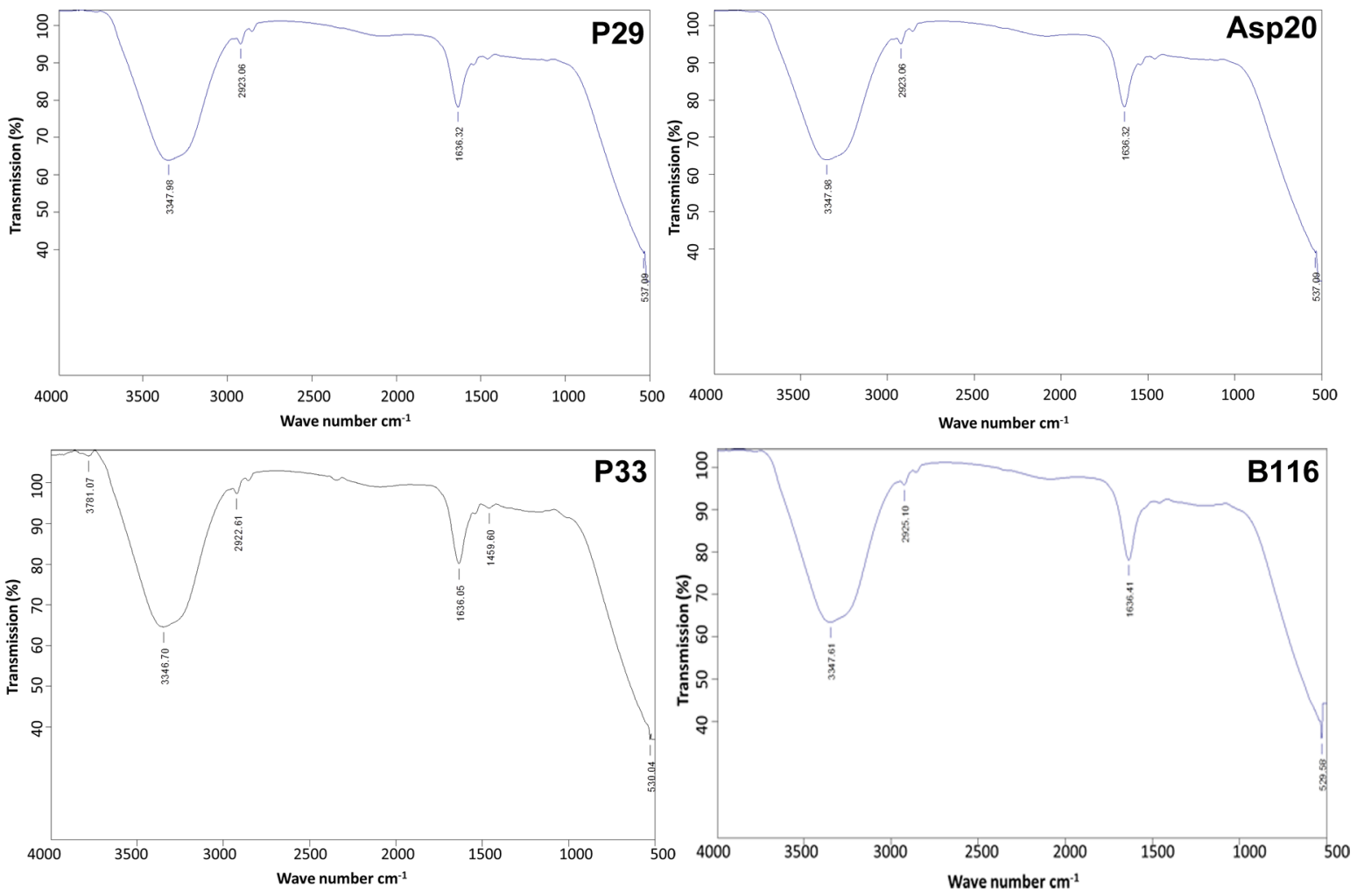

173

Fig3. IR spectrum of cell-free culture filtrates of $\mathrm{ZnO}$ amended MS medium inoculated with different strains of bacteria

\section{Discussion}

Plant growth promoting strains of Pseudomonas, Bacillus and Azospirillum found to solubilize $\mathrm{ZnO}$ and $\mathrm{ZnCO}_{3}$ were formulated and field-evaluated. While trying to understand their mode of action of $\mathrm{Zn}$ solubilization, we found that these strains synthesized $\mathrm{Zn}$ nanoparticles in vitro when cultured in MS broth supplemented with $\mathrm{ZnO}$ or $\mathrm{ZnCO}_{3}$. There were differences among the 
strains in synthesizing different sizes of zinc nanoparticles. According to particle size distribution and SEM analysis, Pseudomonas putida P29 produced smallest zinc nanoparticles of the size 52 $\mathrm{nm}$ followed by Asp20 and B116 produced large particles (106 nm) as against control where the particle size was $5200 \mathrm{~nm}$. The exact mechanism for the synthesis of nanoparticles using biological agents has not yet been elucidated but it has been suggested that various biomolecules are responsible for the synthesis of nanoparticles. The mechanism of extracellular biosynthesis of nanoparticles is proposed as a reductase-mediated reaction, which brings about bioreduction of metal ions and synthesizes nanoparticles (Honary et al., 2012). In the present study, FTIR spectrum of the nanoparticles indicated the presence of various chemical groups, one of which is an amide. An amide I band was observed at 1636 wavecm $^{-1}$, which is the bending vibrational mode of amides. The stretching band of amide at 3346 wavecm $^{-1}$ further confirmed this result. The 1636 wave $\mathrm{cm}^{-1}$ corresponds to amide I due to carbonyl stretch in proteins. FTIR spectrum showed the presence of functional groups such as amide linkages and - $\mathrm{COO}-$, possibly between amino acid residues in protein and the synthesized $\mathrm{Zn}$ nanoparticles. This report is in line with the findings of (Honary 2012) which support the interactions between the proteins and nanoparticles during the biosynthesis. The surface properties of the nanoparticles are known to be one of the most important factors that govern their stability and mobility as colloidal suspensions, or their adsorption or aggregation and deposition. Zeta potential can be related to the stability of colloidal dispersions (Vielkind 2013) as it indicates the degree of repulsion between adjacent and similarly charged particles in dispersion and high zeta potential values indicate high stability and with decrease in the particle size, the stability also decreases. Highest zeta potential of $+179.10 \mathrm{mV}$ was observed for the particle size $106.0 \mathrm{~nm}$ produced by B116 indicating best stability. However, nanoparticles with zeta potential values greater than $+25 \mathrm{mV}$ and $-25 \mathrm{mV}$ typically are stable (Sonika 2015). Hence, it could be inferred that the nanoparticles produced with lower zeta potentials such as $+0.5 \mathrm{mV}$ may not be stable even though they are only $52 \mathrm{~nm}$. Further, low stability nanoparticles tend to form aggregates in the medium, which is influenced by various factors. Aggregation of metal oxide nanoparticles in aqueous solutions depends on ionic strenght, pH, surface charge and charge density (Guzman 2006; Domingos 2009). In the present study also, such aggregation was noticed in cases where the zeta potential was low. Results of particle size distribution clearly indicated that the obtained Zinc nanoparticles are mono as well as poly 
212 dispersed in nature. Samples with very broad size distribution have Poly dispersity index values

$213>0.7$. These findings are supported by the findings of (Anil reddy 2009).

214

215

216

217

218

219

220

221

222

223

224

225

226

227

228

229

230

231

232

233

234

235

236

237

238

239

\section{Conclusion}

Plant nutrient management is an important domain of research and needs understanding of the basic phenomena of uptake and utilization of all essential nutrients. $\mathrm{Zn}$ is an essential nutrient which has a major role in several plant- and human-metabolic pathways. The present finding opens up a new area of research of not only green synthesis of nanoparticles using biological systems but also the dynamics of inter-organism nutrient dependence in the rhizosphere. In this study, we have reported for the first time synthesis of $\mathrm{Zn}$ nanoparticles by the plant growth promoting bacteria with a particle size ranging from 52 to $106 \mathrm{~nm}$. Further research is underway to understand role of these $\mathrm{Zn}$ nanoparticles as a factor in rhizosphere dynamics and modulation, its uptake and transport in crop systems for increasing the productivity.

\section{References}

1. Ahmad A, Mukherjee P, Senapati S, Mandal D, Khan M I, Kumar R, Sastry M (2003) Extracellular biosynthesis of silver nanoparticles using the fungus Fusarium oxysporum. Coll. Surf. B. Biointerfaces 28: 313-18

2. Anilreddy B (2009) Preparation and characterization of iron oxide nanoparticles on disaccharide templates. J. Biomed. Sci. Res. 1:172-83

3. Cattelan A J, Hartel PG, and Fuhrmann J J (1999) Screening for plant growth-promoting rhizobacteria to promote early soybean growth. Soil Sci. Soc. Ame. J. 63: 1670-1680

4. Domingos RF, Tufenkji N, Wilkinson K I, (2009) Aggregation of titanium dioxide nanoparticles: role of a fulvic acid. Environ. Sci. Technol. 43:1282-6

5. Gull FY, Hafeez I, Saleem M and Malik KA (2004) Phosphorus uptake and growth promotion of chickpea by co-inoculation of mineral phosphate solubilizing bacteria and a mixed rhizobial culture. Aust. J. Exp. Agric. 44: 623-628

6. Gurunathan S, Lee KJ, Kalishwaralal K, Sheikpranbabu S, Vaidyanathan R, Eom S H (2009a) Antiangiogenic properties of silver nanoparticles. Biomaterials 30:6341-50 
7. Guzman K A, Finnegan M P, Banfield J F (2006) Influence of surface potential on aggregation and transport of Titania nanoparticles. Environ. Sci. Technol. 40:7688-7693

8. Di Simine CD, Sayer JA, Gadd GM (1998) Solubilization of zinc phosphate by a strain of Pseudomonas fluorescens isolated from a forest soil. Biol. Fertil. Soils 28:87-94

9. Fasim F, Ahmed N, Parsons R, Gadd GM (2002) Solubilization of zinc salts by bacterium isolated by the air environment of tannery. FEMS Microbiol. Lett. 213:1-6

10. Gurunathan S, Kalishwaralal K, Vaidyanathan R, Venkataraman D, Pandian, SRK, Muniyandi J, Hariharan N, Eom, S H, 2009b. Biosynthesis, purification and characterization of silver nanoparticles using Escherichia coli. Coll. Surf. B. Biointerfaces 741:328-35.

11. Honary S, Gharaei-Fathabad E, Paji ZK, and Eslamifar M (2012) A Novel Biological Synthesis of Gold Nanoparticle by Enterobacteriaceae Family. Tropical J Pharma. Res.11 (6) : 887-891

12. Hughes MN and RK Poole RK (1989) Metals and microorganisms. London: Chapman and Hall

13. Kalimuthu K, Suresh Babu R, Venkataraman D, Bilal M, Gurunathan S (2008) Biosynthesis of silver nanocrystals by Bacillus licheniformis. Coll. Surf. B: biointerfaces 65:150-153

14. Klaus T, Joerger R, Olsson E, Granqvist CG (1999) Silver based crystalline nanoparticles, microbially fabricated. Proc. Natl. Acad. Sci. USA 968:13611-14

15. Kloepper JW, Zablokovicz R M, Tipping EM and Lifshitz R (1991) Plant growth promotion mediated by bacterial rhizosphere colonizers. In D. L. Keister \& P. B. Cregan (Eds.) The rhizosphere and plant growth. The Netherlands: Kluwer Academic Publishers $315-26$

16. Leo Daniel Amalraj E, Suseelendra Desai, Devasantosh Mohanty, Goteti Praveen Kumar, Mir Hassan Ahmed SK, Rajashree Pradhan, Sonam Shaheen Khan (2014) Potential Microbial Consortium for Plant Growth Promotion of Sunflower (Helianthus annuus. L). Proceedings of the National Academy of Sciences, India Section B: Biological Sciences DOI 10.1007/s40011-014-0361-4

17. Minaeian S, Shahverdi AR, Nohi AS, Shahverdi HR (2008) Extracellular biosynthesis of silver nanoparticles by some bacteria. J.Sci.I.A.U.17:1-4 
18. Mortvedt JJ (1992) Crop response to level of water soluble zinc in granular zinc fertilizers. Fertilizer Res.33: 249-55

19. Nair B, Pradeep T (2002) Coalescence of nanoclusters and formation of submicron crystallites assisted by Lactobacillus strains. Cryst Growth Des.2: 293-98

20. Martinez-Viveros M, Jorquera, D E, Crowley G, Gajardo ML (2010) Mora Mechanisms and practical considerations involved in plant growth promotion by rhizobacteria. Journal of Soil Science and Plant Nutrition 10:293-19

21. Orhan E, Esitken A, Ercisti S, Turan M, Sahin F (2006) Effects of plant growth promoting rhizobacteria (PGPR) on yield growth and nutrient contents in organically growing raspberry. Sci. Horticulturae 111:38-43

22. Prasad TNVKV, Sudhakar Y, Sreenivasulu P, Latha V, Munaswamy K, Raja Reddy TS, Sreeprasad PR, Sajanlal and Pradeep T (2012) Effect of nanoscale zinc oxide particles on the germination, growth and yield of peanut. J. Plant. Nutrition 35:905-927

23. Rattan RK and Shukla LM (1991) Influence of different zinc carrier on the utilization of micro nutrients by rice. Jounral of Indian Society for Soil Science 39: 808-810

24. Richardson A.E, Simpson RJ, George TS, and Hocking PJ (2009) Plant mechanisms to optimize access to soil phosphorus. Crop Pasture Sci. 60: 124-143.

25. Saifuddin N, Wong CW, Nuryasumira AA (2009) Rapid biosynthesis of silver nanoparticles using culture supernatant of bacteria with microwave irradiation. E-J Chem 6:61-70

26. Sangeetha Nagarajan and Kumaraguru Arumugam Kuppusamy. (2013). Extracellular synthesis of zinc oxide nanoparticle using seaweeds of gulf of Mannar. India J. Nanobiotechnol 11:39

27. Singh AL (1999) Mineral nutrition of groundnut. In: Hemanthranjan (Ed.) Advances Plant Physiology Volume II. Jodhpur, India: Scientific Publishers, 161-200

28. Singh B, Senthil AN, Singh BK, Usha K (2005) Improving zinc efficiency of cereals under zinc deficiency. Curr. Sci. 88:36-44

29. Singh MV (2009) Micronutrient nutritional problems in soils of India and Improvement for human and animal health. Indian Journal of Fertilizer 5:11-26 
30. Sonika K, Jigmet L, Sumit S, Haq Nawaz Sheikh Green hydrothermal synthesis and optical properties of c-Gd2S3 nanoparticles. Applied Nanoscience DOI 10.1007/s13204015-0478-7

31. Sri Sindhura K, Prasad TNVKV, Panner Selvam P, Hussain OM (2014) Synthesis, characterization and evaluation of effect of phytogenic zinc nanoparticles on soil exoenzymes. Applied Nanoscience 4:819-827

32. Suseelendra Desai, Praveen Kumar G, Uzma Sultana, Sravani Pinisetty, Mir Hassan Ahmed SK, Leo Daniel Amalraj E and Gopal Reddy (2012). Potential microbial candidate strains for management of nutrient requirements of crops. African Journal of Microbiological Research 6:3924-3931

33. Venkatakrishnan AS, Rajendran K, Nandagopal A, Ramasamy M, Manoharan ML, and Ramanathan S (2003). Yield enhancement of rice under irrigated low land condition. Research on Crops 4: 31-33

34. Venkateswarlu B and Wani SP (1999). Bio-fertilizers An Important Component of Integrated Plant Nutrient Supply in Drylands. In Fifty Years of Dryland Agricultural Research in India (Eds.) H.P. Singh, Y.S. Ramakrishna, K.L. Sharma and B. Venkateswarlu). Hyderabad, India: Central Research Institute for Dryland Agriculture. 379-394

35. Vielkind M, Kampen I, and Kwade A (2013). Zinc Oxide Nanoparticles in bacterial growth medium Optimized dispersion and growth Inhibition of Pseudomonas putida. Advances in Nanoparticles 2:287-293

36. White C, Sayer J.A and Gadd G.M. (1997) Microbial solubilization and immobilization of toxic metals Key biogeochemical processes for treatment of contamination FEMS Microbiol. Rev 20: 503-516

37. Zhang HLi, Lu Y, Sun D, Lin X, Deng X (2005) Biosorption and bioreduction of diamine silver complex by Corynebacterium. J Chem Technol Biotechnol. 80:285-290. 